\title{
Individual foraging, activity level and longevity in the stingless bee Melipona beecheii in Costa Rica (Hymenoptera, Apidae, Meliponinae)
}

\author{
J.C. Biesmeijer ${ }^{1}$ and E. Tóth ${ }^{2}$
}

Ethology and Socio-Ecology Group, Laboratory of Comparative Physiology, Utrecht University, P.O. Box 80.086, NL-3508 TB Utrecht, The Netherlands

1 Present address: P.O. Box 2270-3000 Heredia, Costa Rica, e-mail: kbiesmei@una.ac.cr.

2 Present address: Department of Ecology and Evolutionary Biology, Rice University, Main Street 6100, Houston, TX 7705-1892,USA, e-mail: etoth@ruf.rice.edu

Key words: Stingless bees, Melipona, foraging activity, survival, specialisation, foraging efficiency.

\section{Summary}

Foraging behaviour of individually marked workers of Melipona beecheii (Meliponinae) was monitored in Costa Rica to investigate individual specialisation for different materials and how this influences foraging longevity. The majority of the individuals harvested one commodity (pollen, nectar or resin) during a single day. Half of the age-marked foragers specialised on nectar or pollen during their complete foraging career, the other half collected two or three commodities. Most members of the latter group switched daily from early morning pollen (or resin) collecting to nectar collecting. Life-long foraging of one-material collectors was not more efficient than that of two-material collectors. The groups of foragers differed significantly in activity patterns and longevity: activity was traded off with longevity. Nectar foragers were active all day and died after an average of 3 foraging days. Pollen foragers were active for 1-3 hours per day, but lived for 12 days on average. However, pollen foragers and nectar foragers performed a similar number of flights in their career.

How bees become pollen, nectar or mixed foragers is not clear. Age and performance of pre-foraging hive tasks did not influence forager specialisation in M. beecheii.

\section{Introduction}

Social insect colonies consist of two interdependent levels of organisation, the individual and the colony level. Individual behaviour is regulated by colony needs, but in turn also influences the internal state of the colony. This relationship is especially clear in those members of the society that maintain the colony's contacts with the environment, e.g., foragers. They react to changes in colony need by initiating food collecting at younger age or by increasing their foraging activity when the food reserves are low (Fewell and Winston, 1992). Also, additional workers are allocated 
to nest repair when the nest is damaged (O'Donnell and Jeanne, 1990). Individuals alter the colony status by increasing the amount of food that is stored or by repairing the nest. Individual foraging decisions are not only directed by colony needs, but also by previous experience probably through simple feedback mechanisms (Pasteels et al., 1987). This may explain the fixation of foragers to collecting only one type of food (Lindauer, 1952) or construction material (O'Donnell and Jeanne, 1990) for several hours or days. Each individual has its own behavioural history. As a result each foraging career is unique in terms of material specialisation, activity level and longevity.

O'Donnell and Jeanne (1992) studied the effect of activity level and material specialisation on forager mortality in Polybia occidentalis wasps. They conclude that mortality increases with foraging activity and that gathering food is riskier than collecting nest materials. Similar patterns are found for honeybees, where highly active foragers are short-lived compared to less active foragers (Neukirch, 1982) and increased effort, induced by attaching permanent weights to bees, also reduces life-span (Wolf and Schmid-Hempel, 1989). Differential survival of collectors of different materials has not been addressed in detail in social bees. Moreover, studies on survival of social bee foragers do not distinguish between the various types of foragers (Sakagami and Fukuda, 1968; Simões and Bego, 1991), although foragers do specialise on materials (Lindauer, 1952; Ribbands, 1952; Sommeijer et al., 1983).

Few studies deal with individual behaviour of foragers of stingless bees (Hymenoptera; Apidae; Meliponinae), a pantropical group of more than 400 species of eusocial bees that make up about half of the flower visiting insects in the tropical lowlands of the Americas (Heithaus, 1979). Up to $75 \%$ of the foragers of stingless bees seem to be fixated on collecting one type of material over a period of days (Inoue et al., 1985; Sommeijer et al., 1983). These studies are either based on very few foragers (Inoue et al., 1985) or on few flights per forager (Sommeijer et al., 1983). Life-long careers of stingless bee foragers have not been studied in detail before. Although forager longevity was found to be highly variable (Sommeijer, 1984), it is not known whether this was caused by variation in the costs of different behaviours or by other factors (e.g., genetics, morphology, physiology).

The aim of this study was to analyse whether activity level and type of material that is collected are related to the longevity of stingless bee foragers, in a similar way as in honeybees and swarm-founding wasps. Such characteristics of individual foraging are important components of the dynamics of colony foraging. We first describe daily and life-long patterns of individual foraging of stingless bees of the species Melipona beecheii. From these data we analyse patterns of longevity and foraging activity and some possible factors that may influence these patterns. 


\section{Material and methods}

\section{Study sites and bee colonies}

The study was carried out in Costa Rica at two sites:

1) One colony of Melipona beecheii (Meliponinae) was studied in Pozo Azul de Abangares, Guanacaste Province $\left(10^{\circ} 10^{\prime} \mathrm{N}\right.$; $85^{\circ} 00^{\prime} \mathrm{W}$; alt. $\left.200 \mathrm{~m}\right)$. Pozo Azul is situated in the tropical dry forest zone. The observations took place in the dry season of 1993 (between February 22 and April 3). Annual rainfall at this site is about $2000 \mathrm{~mm}$. Rainfall was almost absent during the observation period. Temperature normally ranged from $21^{\circ} \mathrm{C}$ to $39^{\circ} \mathrm{C}$ with extreme values of $17^{\circ} \mathrm{C}$ and $41^{\circ} \mathrm{C}$. Observations in Pozo Azul consisted of: 1) recording hive-activities and foraging behaviour of 45 age-marked bees over a period of 32 days, and 2) Six days of video recordings of entries and exits of all marked bees of the colony (a total of 112 marked bees performed at least one flight during the recordings).

2) A second colony of Melipona beecheii (Meliponinae) was studied in El Sur de Turrubares, Puntarenas Province $\left(9^{\circ} 45^{\prime} \mathrm{N}\right.$; $84^{\circ} 35^{\prime} \mathrm{W}$; alt. $\left.180 \mathrm{~m}\right)$. El Sur is situated in the humid tropical forest zone. The observations took place in the wet season of 1994 (between May 9 and July 28). Annual rainfall at El Sur is about 3000 mm; during the observation period rainfall occurred every two or three days and normally started in the afternoon. Temperature normally ranged from $20^{\circ} \mathrm{C}$ to $35^{\circ} \mathrm{C}$ with extreme values of $16^{\circ} \mathrm{C}$ and $40^{\circ} \mathrm{C}$. The entries and exits of individually marked foragers were observed.

Both bee colonies were installed inside a house and were connected to the outside through a transparent plastic tube. The colonies were transferred to the observation hive several months before observations started. The entrance of each colony was colour-marked to facilitate orientation. The two colonies of Melipona beecheii Bennett used were:

Colony 1 (Pozo Azul): Most data were collected from this colony. The observationhive consisted of three plywood compartments $(1 \mathrm{~cm}$ thick) all covered with glass, to facilitate observation of the colony: a brood chamber $(151 \times 15 \mathrm{w} \times 13 \mathrm{~h} \mathrm{~cm})$ containing the brood combs surrounded by involucrum; a marking annex $(24 \times 15 \times 6 \mathrm{~cm})$ where old comb could be placed to facilitate daily marking of newly emerged bees; and a food-storage chamber $(49 \times 20 \times 6 \mathrm{~cm})$ containing honey and pollen storage pots, resin-mud and wax deposits, and a waste dump. Plastic tubes connected the compartments. The worker population decreased from 450 bees at the start of the observations to some 350 bees at the end, due to brood cannibalism and low brood production. Total food storage increased from 40 pots (all nectar) to 58 pots (of which 3 contained pollen) during the observation period. No pollen was stored at the start of the observations, because part of the pollen stores were removed one month before observations started during another experiment.

Colony 2 (El Sur) was housed in a one compartment hardwood box $(60 \times$ $20 \times 20 \mathrm{~cm}$; walls $2.5 \mathrm{~cm}$ thick). To leave or enter the bees had to walk $15 \mathrm{~cm}$ includ- 
ing two curves to slow them down. This is to facilitate observation of flight activity. The colony consisted of about 2500-3000 bees and ample food pots (nectar and pollen) throughout the observations.

\section{Marking procedures}

Bees of colony 1 were marked upon emergence. This was accomplished by removing mature brood comb from the brood compartment to the marking-annex. At least once a day newly emerged bees were marked. Coded paper tags were glued on the thorax of the bees. More than 350 age-marked bees were available at the start of the video-observations.

To analyse life-long foraging careers and the relation between foraging and previous hive activities, a group of 45 bees of colony 1 was individually re-marked with distinct colour patterns when they were about 2 weeks old; the letter-codes are not adequate for rapid identification of forager movements.

In colony 2 foragers were individually marked by gluing coloured paper tags to their thorax prior to and during the observations.

\section{Flight activity}

Flight activity was recorded in both colonies. Exits and entries of marked foragers were observed; time, load type and size (of pollen loads only) were registered on audio tapes (direct observations) or by video recordings. In 1993 the colony in Pozo Azul was observed from dawn till dusk from February 22 to February 28 (video recordings) and from March 1 to April 3. From March 1 to April 3 the exits and entries of the 45 colour-marked bees and of all the returning pollen foragers were recorded by direct intranidal observation. By examining the first trophallactic interaction between a returnee and a nestmate we could distinguish nectar collecting flights (returnee gives nectar to nestmate) from unsuccessful flights (returnee "begs" for nectar, as do returning pollen collectors). Resin and mud could not be distinguished with certainty from the video tapes and will be referred to as resin for those observations. The movements of foragers of colony 2 were recorded by direct observation between June 6 and June 23 in 1994 from dawn till noon daily (interrupted for marking bees from 9:00-10:00).

\section{Intranidal behaviour recordings}

In order to study the relation between pre-foraging behavioural repertoire and foraging career, the behaviour of the 45 colour-marked bees of colony 1 was scan-sampled 12 times a day from February 22 to April 3, prior to and simultaneously with flight activity recordings. The first observation was at $5: 20$ followed by observations every 90 minutes from 7:00-22:00 (last 5 days till 20:30). A complete scan procedure lasted 10-15 minutes. It included the recording of the location in the hive and the first behaviour observed for each member of the group. 
The following locations and behaviours were used in the analyses:

Locations: 1 Comb; 2 Wall; 3 Area near entrance ( $5 \mathrm{~cm}$ around entrance tube); 4 Empty food pot; 5 Food pot under construction; 6 Open nectar pot; 7 Closed nectar pot; 8 Open pollen pot; 9 Closed pollen pot; 10 Resin/mud deposit; 11 Waste deposit; 12 Within entrance tube.

Behavioural acts recorded: A total of 27 different behaviours were distinguished (including cell building, cell provisioning, waste removal, fanning). Only 8 of these occurred regularly enough to be included in our analyses:

1 Antennate other bee: Bee touches a body-part of another bee in rapid movements with the antennae slightly curved. The bees stand vis-á-vis and antennate each other. Excluded: antennations during mandibular contact and nectar transfer.

2 Mandibular contact with other bee: Bees stand vis-á-vis and mutually contact each others mandibles while antennating. Excluded: nectar transfer.

3 Give nectar: Trophallactic nectar transfer. The bees face each other standing on their middle and hind legs. The donor lifts her forelegs from the floor. The forelegs of the receiver often tap the forelegs (or thorax) of the donor, especially at the end of the process. The donor opens her mandibles, the receiver places her proboscis between the mandibles of the donor and takes up the liquid expelled by the donor.

4 Receive nectar: Bee takes up nectar from another bee by trophallaxis. See "give nectar".

5 "Dehydrate" nectar: Bee expels a droplet of nectar between her mouth parts and stirs it with part of her labrum. The droplet is sometimes imbibed and expelled again.

6 Move: The bee displaces itself forward in any direction.

7 Stand: The bee is motionless.

8 Autogroom: The bee rubs a part of her body with one or more of her legs.

The aim of the observation of the intranidal behaviour was to study a possible relation between hive activities in the pre-foraging period and foraging career. In addition to an individual analysis we performed an analysis of the different groups of foragers based upon the life-long foraging activity data obtained. Foragers were identified as pollen bees, nectar bees, pollen-nectar foragers (bees that collected pollen and nectar on the same day) or mix bees (bees that collected any other combination of materials during their foraging career). Three different portions (short, intermediate and long) of the pre-foraging period were chosen for the analysis: 1) from 14 days of age until foraging started; 2) last 13 days before foraging started (this period includes all orientation flights); and 3) last three days before foraging started (this period includes the longer non-successful flights that many foragers performed before becoming specialised foragers). For the comparisons we used the repetitive Kolmogorov-Smirnov test (KS-test), which compares the distribution of relative frequencies of the whole repertoire of behavioural acts of the different forager groups (for explanation see Kolmes, 1985). 


\section{Life span, survival curves, activity level and efficiency}

Life span of the foragers of the $M$. beecheii cohort was calculated by taking the last date a bee was observed alive as her last day alive. Only half of the bees had died at the end of the observation period. Additional checks on the presence of the survivors were performed 12 and 32 days after regular observations ended.

Survival curves were calculated for all bees, and for the different forager groups (nectar bees; pollen bees; mix bees). Survival curves were compared among forager groups by using a Peto-Wilcoxon log-rank test. The Chi-square test was used to test for randomness of transitions between the materials that were collected on successive flights.

Activity level was measured in several ways, because we did not have prior indications of which measure would be the most appropriate (see also O'Donnell and Jeanne, 1992): A) foraging tenure: total number of active days (days on which at least one flight was performed); B) total number of flights in career; C) number of flights per active day $(=\mathrm{B} / \mathrm{A})$; D) total foraging time in career (in hours); E) foraging time per active day $(=\mathrm{D} / \mathrm{A})$.

The relation between activity level and foraging career was tested using the Spearman rank correlation test (SRCT).

To analyse the efficiency of the different groups of foragers we calculated the percentage of successful flights (at least some food or nest material collected) and the average flight time per load measured over the whole career (total flight time divided by number of loads). Degree of specialisation was calculated using the Shannon-diversity index, H' (Shannon and Weaver, 1949).

\section{Results}

\section{Task fixation and task switching}

The video-recordings of individual foraging patterns over the day in Melipona beecheii (Fig. 1) showed that 65 bees ( $71 \%$ ) collected only one type of material in a single day. Other individuals $(15 \%)$ switched from pollen collecting to nectar collecting in the course of the morning or performed one or more switches within a day other than from pollen to nectar $(14 \%)$. On two consecutive flights a bee normally collected the same type of material (Table 1a). Almost all possible transitions from one material to another occurred, but in a non-random way (Chi-square $=1139.15$; $\mathrm{p}=0.0001 ; \mathrm{df}=4)$. Most common switches were from pollen to nectar and from $\mathrm{resin} / \mathrm{mud}$ to nectar.

Most $M$. beecheii foragers started the day with collecting the same type of material that they collected last on the previous day (Table 1b). Again all switches occurred in a non-random way (Chi-square $=22.36 ; \mathrm{p}=0.0002 ; \mathrm{df}=4$ ). The most common switch was from nectar collecting at the end of one day to pollen collecting on the first flight of the next day.

Approx. $48 \%$ of bees collected only one material during their foraging career (Table 2). About $40 \%$ of the individuals collected both pollen and nectar, many of them on the same day. Pollen was mostly collected first in a day by such bees. 


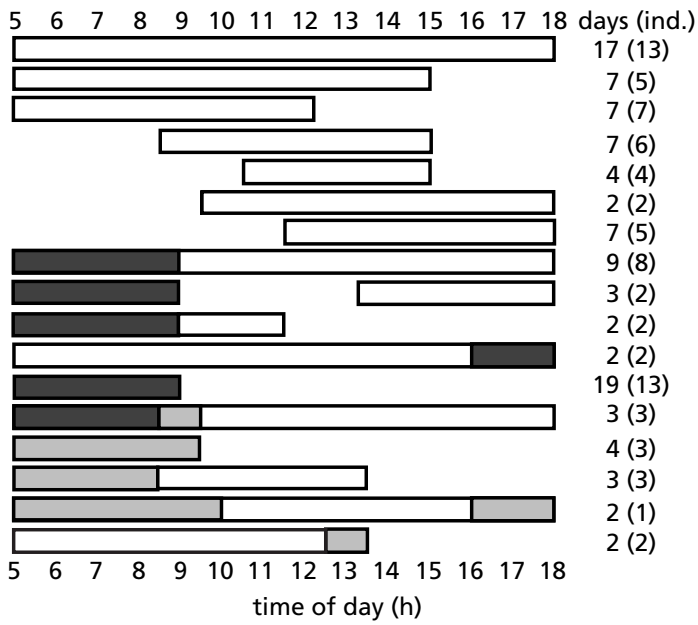

Figure 1. Daily foraging patterns of M. beecheii foragers in Pozo Azul. White bars: nectar; light grey bars: resin; dark grey bars: pollen. Data from 6 days of video recordings. Given are the cumulative number of 'bee-days' (irrespective of bee identities) that each foraging pattern occurred (days) and the number of individual bees that performed each pattern (bees)

Table 1. Frequency of switches in the type of material that was collected. Data from three days of video observations on $M$. beecheii in Pozo Azul. a) switches from one flight to the next within a day; b) switches from the last flight of one day to the first flight of the next day

a

\begin{tabular}{|c|c|c|c|c|}
\hline & & Next fl & & \\
\hline & & pollen & nectar & $\mathrm{resin} / \mathrm{mud}$ \\
\hline Previous flight & $\begin{array}{l}\text { pollen } \\
\text { nectar } \\
\text { resin/mud }\end{array}$ & $\begin{array}{r}67 \\
2 \\
0\end{array}$ & $\begin{array}{r}19 \\
838 \\
10\end{array}$ & $\begin{array}{r}5 \\
7 \\
25\end{array}$ \\
\hline
\end{tabular}

b

\begin{tabular}{|c|c|c|c|c|}
\hline & & First fl & ext day & \\
\hline & & pollen & nectar & $\mathrm{resin} / \mathrm{mud}$ \\
\hline Last flight & pollen & 10 & 4 & 1 \\
\hline Previous day & nectar & 11 & 30 & 4 \\
\hline & resin/mud & 1 & 2 & 4 \\
\hline
\end{tabular}


Table 2. Collection of nectar, pollen and nest materials by workers in three observation series: M. beecheii Pozo Azul: 6 day series (video recordings) and whole career (combined observations). M. beecheii El Sur: 16 days series. The $M$. beecheii series in El Sur concentrated on pollen foraging and therefore do not relate directly to the colony pattern

\begin{tabular}{l|lll}
\hline & \multicolumn{2}{l}{ M. beecheii Pozo Azul } & M. beecheii El Sur \\
\cline { 2 - 4 } & 6 days (video) & whole career & 16 days \\
\hline 1 material & $38(51 \%)$ & $48(48 \%)$ & $97(60 \%)$ \\
pollen (P) & 7 & 12 & 70 \\
nectar (N) & 25 & 33 & 20 \\
resin/mud (R) & 6 & 3 & 7 \\
\hline 2 materials ${ }^{1}$ & $28(38 \%)$ & $39(39 \%)$ & $62(38 \%)$ \\
\hline $\mathrm{P}+\mathrm{N}$ & 18 & 28 & 57 \\
$\mathrm{P}+\mathrm{R}$ & 2 & 1 & 4 \\
$\mathrm{~N}+\mathrm{R}$ & 8 & 10 & $3(2 \%)$ \\
\hline 3 materials ${ }^{1}$ & $8(11 \%)$ & $13(13 \%)$ & 3 \\
\hline $\mathrm{P}+\mathrm{N}+\mathrm{R}$ & 8 & 13 & 2 \\
\hline
\end{tabular}

${ }^{1}$ The different materials were collected on separate flights.

\section{Complete foraging careers}

Four types of foragers could be distinguished among the 45 intensively studied $M$. beecheii bees: specialists in collecting pollen, specialists in nectar collecting, foragers that performed a daily switch from pollen collecting to nectar collecting (further referred to as pollen-nectar foragers), and mixed foragers that collected a combination of materials (other than pollen and nectar within one day). Entire foraging careers were recorded for 29 bees in colony 1 . The following descriptions are mainly based on this group:

Pollen foragers ( $\mathrm{n}=9$; Fig. 2a), collected pollen on more than $80 \%$ of their flights.

They did not collect pollen and nectar in the same flight. Four bees collected pollen exclusively. Pollen specialists had careers lasting 4 to 19 days (12 days on average). Pollen bees were typically active for 1-3 hours a day in the early morning. During two observation days (March 26 and 27, 1993) pollen collection lasted much longer; two bees continued till 15:20 and 17:50 respectively.

Nectar foragers ( $n=13$; Fig. 2b), collected nectar on more than $80 \%$ of their flights. Nine bees collected nectar exclusively. Nectar specialists died after having collected nectar actively for 3 days on average (range 2-4 days) and 4-10 hours per day. They started collecting every morning between 5:30 and 7:30 and stopped between $12: 30$ and 16:20.

Pollen-nectar foragers ( $\mathrm{n}=5$; Fig. $2 \mathrm{c})$ collected pollen and nectar on separate flights within the same day for at least one day. They actively collected (more than 
4 hours per day) both materials for 1 to 5 days ( 3 days on average). These bees collected pollen first (from 5:30-9:00) followed by nectar collecting till 17:00 or 18:00. This group of foragers is not as coherent as the above mentioned groups. Before collecting both materials on the same day, 1 bee collected pollen for 3 days, whereas 2 bees collected nectar for 1 and 2 days respectively. After the pollen-nectar period 3 bees collected nectar exclusively for 1, 2, and 3 days respectively.

Mixed foragers $(\mathrm{n}=11)$ did not collect one commodity on more than $80 \%$ of their trips. Two of these foragers are special in that they collected resin for 4 and 11 days respectively every day from 5:30-8:00. They collected other materials before and after. These two bees showed similarities with pollen foragers, but were too few to include in a separate group.

\section{Age and type of food or nest material collected}

In the cohort of age-marked $M$. beecheii workers, individual bees performed their first flight at an age of 33 days on average ( $\mathrm{sd}=5 ; \mathrm{n}=42$; range 16 to over 60 days). These first flights were probably orientation flights, because they normally lasted

a

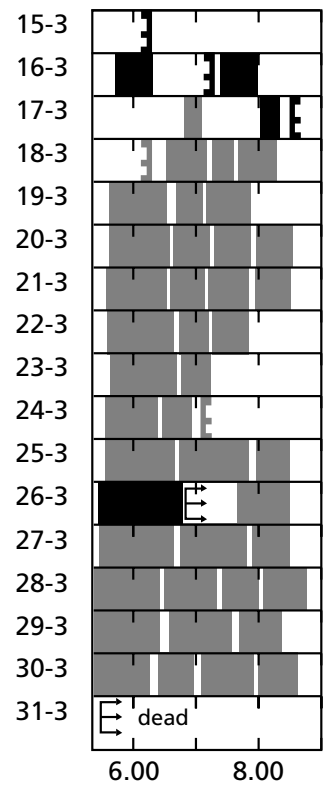

b

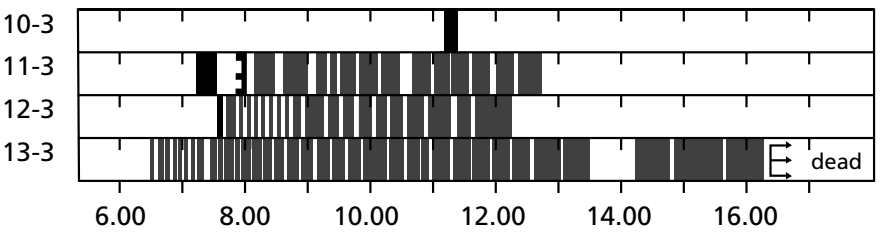

C

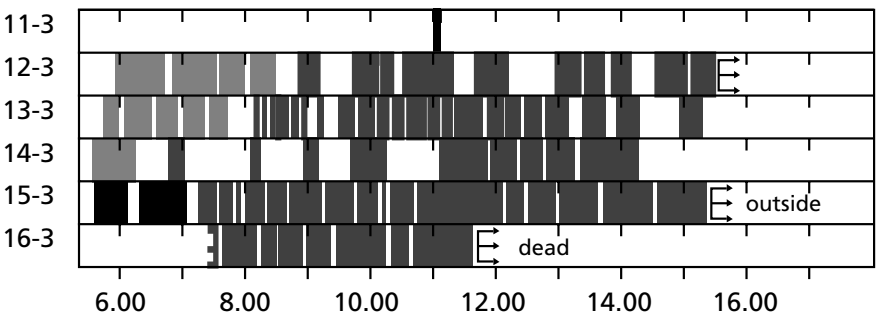

Figure 2. Life-long foraging careers of three individual M. beecheii workers in Pozo Azul. a) exemplary career of pollen forager; b) career of nectar forager; c) career of pollen/nectar forager. Each bar represents one foraging day (between March 8 and March 31,1994) from 5.00 to 18.00 hours. Grey areas indicate nectar flights, light grey areas indicate pollen flights, black areas indicate unsuccessful flights (no load was collected). Width of area indicates flight duration. Areas dented at the right side indicate flights of which time of entry was not recorded. Of areas dented at the left side exit time was not recorded 
5-10 minutes and the bees did not collect any material. After these orientation flights some bees were involved in waste removal. We excluded "orientation" flights and waste removal flights from our calculation of first foraging activity. First foraging flights were performed at an average age of 40 days $(\mathrm{sd}=7.9 ; \mathrm{n}=35$; range: 16 to over 60 days). Some bees performed flights before observations started, and at the end of the observations several bees had not performed any flights, despite their age of 49 days. From an age of 20 days onward a constant proportion of the bees started foraging (Fig. 3). The type of material that was collected first did not affect the onset of foraging (Mann-Whitney U-test pollen vs. nectar: $\mathrm{z}=-0.4$, $\mathrm{p}=0.69$; pollen: average 41 days, $\mathrm{sd}=10, \mathrm{n}=9$; nectar: average 40 days, $\mathrm{sd}=8, \mathrm{n}=22$; resin: 37 days, $\mathrm{n}=1$ ).

\section{Pre-foraging hive activities and type of food or nest material collected}

The 45 bees of the cohort were 12-19 days old at the start of the scan observations. A total of 15,116 behaviour scans were recorded, $66 \%$ of which consisted of moving (7,025 scores) and standing still (2,961 scores). The individual bees were observed 209 times on average (range 57-337). We distinguished 4 types of foraging careers (see above), but for this analysis combined pollen-nectar bees and mixed foragers into one group to increase sample size. The three groups of foragers performed similar intranidal behaviour in their pre-foraging period as well as in their foraging period (all comparisons $\mathrm{p}>0.05$; repetitive KS-test). No differences were found in the locations they visited or in the interaction of behaviour and location (all comparisons $\mathrm{p}>0.05$; repetitive KS-test). Analysis of individual bees, however, revealed that within all groups some individuals differed significantly from others in the behaviour performed, the location visited or

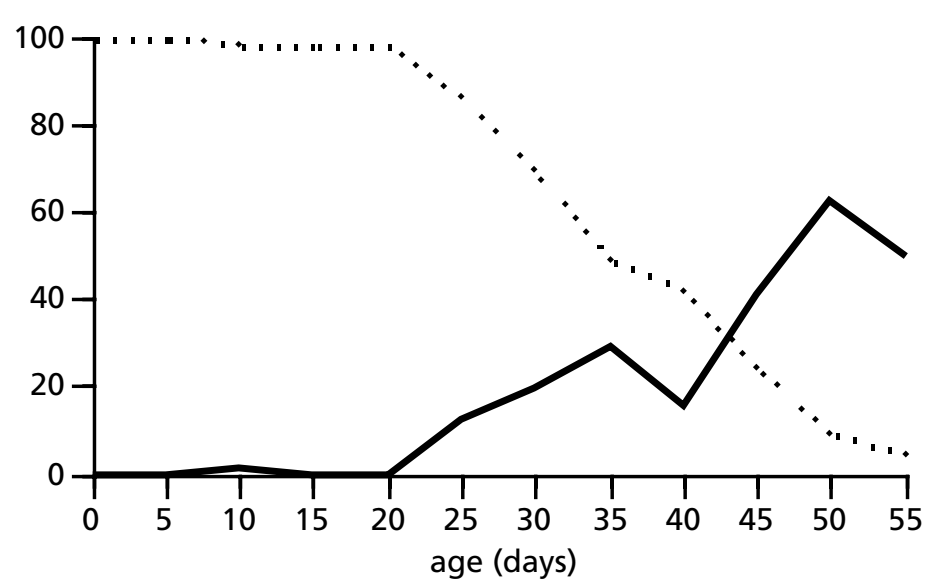

Figure 3. Relation between age and initiation of foraging in $M$. beecheii Pozo Azul (N=37). Dotted line: percentage of bees that not yet initiated foraging. Solid line: percentage of remaining bees that initiates foraging in given age-interval 
the combination of behaviour and location. The behaviours that caused the differences in all comparisons were "move" and "stand" and to a lesser extent "dehydrate nectar" and "autogroom". Overall, the results did not reveal any relation between the intranidal behavioural acts (that occurred frequently enough to include in the analysis) before foraging started and the type of foraging career that followed.

\section{Longevity, activity level and foraging career}

The life-span of the bees in the $M$. beecheii age-cohort was 51 days on average $(\mathrm{sd}=15 ; \mathrm{N}=45)$ when the last day observed alive was taken as the day of death. Half of the bees were alive at the end of the observation period (they were between 49 and 59 days old). Five bees lived over 70 days, two over 86 days, one of these two over 101 days. Longevity was not different for the various groups of foragers (Kruskal-Wallis test: $\mathrm{H}=0.734 ; \mathrm{p}=0.69)$.

The length of the foraging career (in days) was negatively correlated with activity level, measured as: a) number of flights performed per day (Spearman Rank Correlation Test (SRCT) $\mathrm{r}=-0.77, \mathrm{p}<0.01, \mathrm{~N}=16$ ); and, $\mathrm{b}$ ) number of foraging hours per day (SRCT, $\mathrm{r}=-0.67, \mathrm{p}<0.05, \mathrm{~N}=16$ ). For the bees that collected both pollen and nectar at least once in their lives we found that a foragers' career was shorter (in days) when a higher proportion of its flights was devoted to nectar collecting (SRCT, $\mathrm{r}=-0.639, \mathrm{p}<0.05, \mathrm{~N}=16$ ).

A longer foraging career (in days) meant that the bee foraged more hours in total (SRCT, $\mathrm{r}=0.55, \mathrm{p}=0.03, \mathrm{~N}=16$ ), but not that a higher number of flights was performed (SRCT, $\mathrm{r}=0.31, \mathrm{p}=0.23, \mathrm{~N}=16$ ). The length of the foraging career was not related to the age at which the bee first foraged (SRCT, $\mathrm{r}=-0.24, \mathrm{p}=0.35$, $\mathrm{N}=16$ ).

The type of material that a forager collected significantly influenced the total number of hours a bee foraged in her career (Fig. 4 b; Peto-Wilcoxon-test; 3 groups, $\mathrm{df}=2 ; \mathrm{Z}=6.80, \mathrm{p}=0.03 ;$ Npollen $=8$, Nnectar $=13$, Npollen-nectar $=4)$. Fifty percent of the pollen-bees foraged for 36 hours or more (maximum 52 flight hours), whereas none of the nectar-bees performed more than 24 flight hours, which was about average for mixed foragers. The $50 \%$ percentile of total flight hours for nectar bees is 16 hours and the maximum 24 hours.

Foraging tenure (in days) was significantly shorter for nectar foragers and mix foragers than for pollen bees (Fig. 4a; Peto-Wilcoxon-test; $Z=2.63, p=0.009$; $\mathrm{Np}=8, \mathrm{Nn}+\mathrm{pn}=17)$. However, total number of flights performed in the complete foraging career was not significantly different for nectar bees and pollen bees (Fig. 4c; Mann-Whitney U-test: $\mathrm{z}=-0.29, \mathrm{p}=0.772$; nectar foragers: average $=59, \mathrm{n}=13$; pollen foragers: average $=52, \mathrm{n}=8$ ). Pollen-nectar foragers were too few to analyse.

\section{Life-time efficiency of foragers}

The degree of specialisation of the M. beecheii foragers, measured as Shannon's H', was not related to the percentage of successful flights (flights on which a load was 

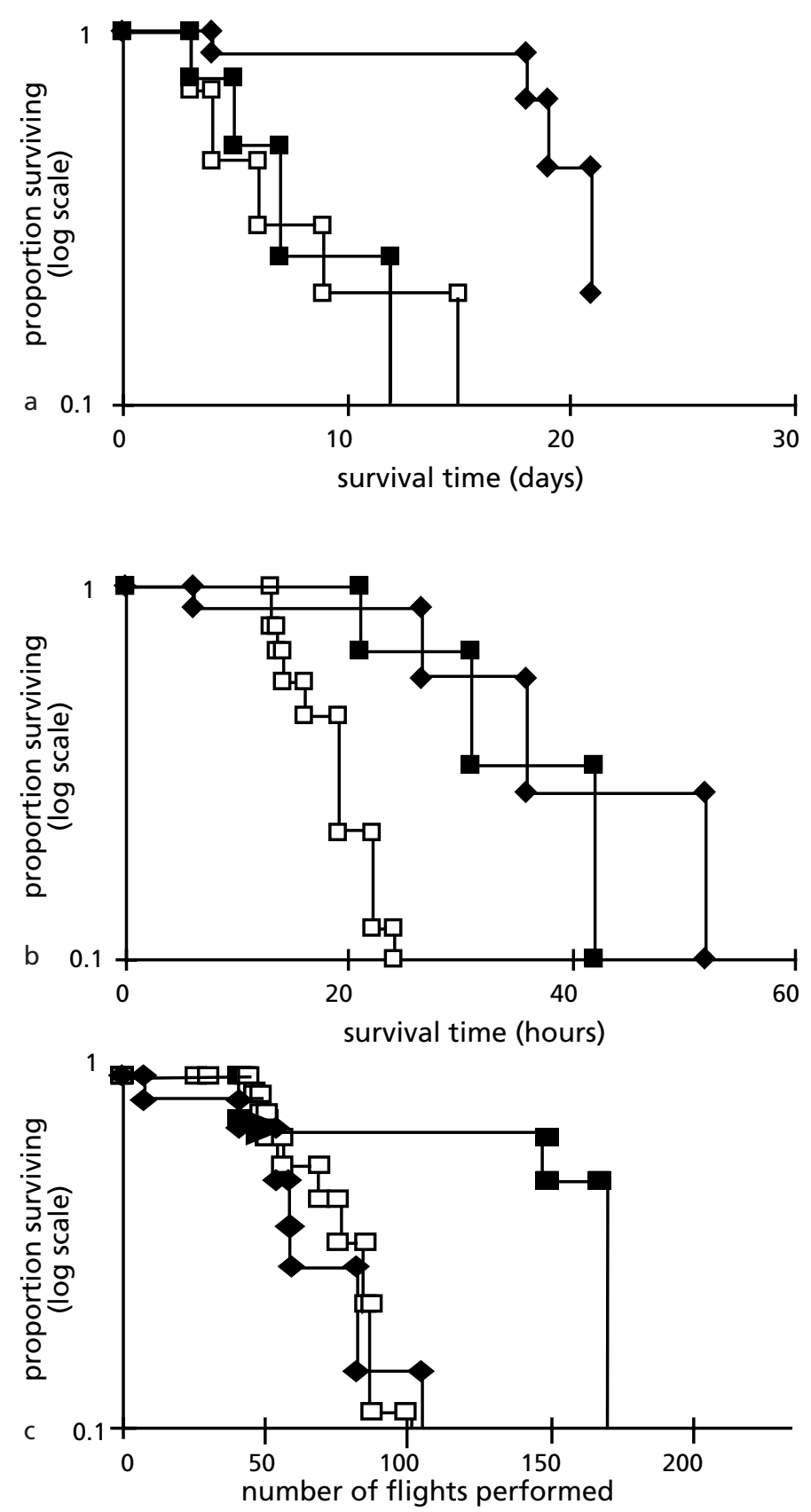

Figure 4. Duration of foraging careers for different types of $M$. beecheii foragers: (a) foraging tenure in days; (b) tenure in flight hours; (c) number of flights performed. Open squares: nectar foragers $(\mathrm{N}=13)$; closed diamonds: pollen foragers $(\mathrm{N}=8)$; closed squares: pollen-nectar foragers $(\mathrm{N}=4)$ 


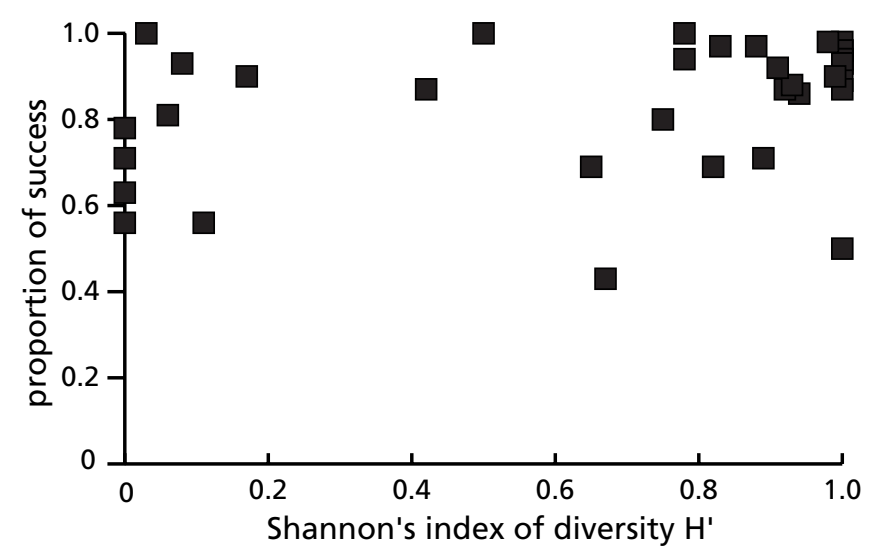

Figure 5. Diversity of foraging career in relation to foraging success (number of loads/number of flights) of $M$. beecheii foragers. The relation is not significant (SRCT: $r h o=-0.012 ; \mathrm{z}=-0.07 ; \mathrm{p}=0.944 ; \mathrm{n}=36$ )

collected) performed by foragers (Fig. 5; SRCT: rho $=-0.012 ; \mathrm{z}=-0.07 ; \mathrm{p}=0.944$; $\mathrm{n}=36$ ). However, nectar foragers had a higher success rate than pollen foragers (Mann-Whitney U-test: $\mathrm{z}=-2.067, \mathrm{p}=0.039$; pollen: average success $76 \%, \mathrm{n}=8$; nectar: average success $89 \%, n=13$ ). The life-time success of the pollen-nectar foragers is $75 \%$, which is not significantly different from the other groups. The duration of pollen collecting flights and nectar collecting flights was not different for specialist and generalist foragers. Nectar specialists $(\mathrm{N}=8)$ needed $15.6 \pm 2.3 \mathrm{~min}$ on average $(\mathrm{n}=553$ flights $)$ to collect a nectar load and mixed foragers $(\mathrm{N}=5)$ $16.8 \pm 3.5 \min (\mathrm{n}=244)$ (Mann-Whitney test, $\mathrm{z}=-0.878 ; \mathrm{p}=0.38)$. Pollen was collected by the specialist foragers $(\mathrm{N}=4)$ in $25.1 \pm 11.6 \mathrm{~min}$ on average $(\mathrm{n}=207)$, whereas pollen collecting flights performed by generalists $(\mathrm{N}=5)$ lasted on average $24.0 \pm 6.3 \min (\mathrm{n}=145)$ (Mann-Whitney test, $\mathrm{z}=-0.245 ; \mathrm{p}=0.81)$. For all individual bees pollen collecting flights lasted longer than nectar collecting flights.

\section{Discussion}

\section{Specialisation on materials}

According to the existing theory on task allocation in social insects (e.g. Oster and Wilson, 1978) and observational studies on bees (Lindauer, 1952; Ribbands, 1952; Sommeijer et al., 1983) individual foragers of Melipona were expected to specialise on collecting one type of food. About $70 \%$ of the M. beecheii foragers fixated on collecting one type of material on a daily basis and about $50 \%$ over a sequence of days or during complete foraging careers. Sommeijer et al. (1983) observed that more than $70 \%$ of the foragers of Melipona favosa collected only one type of food (nectar or pollen) over a period of days. This high percentage for M. favosa is probably influenced by their low sampling intensity that included only about 4 flights per forager. More extensive studies on honeybees (Ribbands, 1952) and Trigona 
stingless bees (Inoue et al., 1985) indicate that the $50 \%$ one-material specialists in $M$. beecheii may be a more common pattern.

Most bees that collected more than one type of material within a day reflected the foraging pattern of collecting pollen in the early morning and nectar during most of the day observed in various species of Melipona (Roubik and Buchmann, 1984; M. beecheii: van Nieuwstadt and Biesmeijer, unpubl. data). This colony foraging pattern is shared by the Sumatran Trigona species studied by Inoue and co-workers, but is less pronounced in temperate or tropical Apis species (Free, 1968; Roubik, 1989). Foragers that performed a switch from pollen to nectar collecting within a day are reported by Inoue et al. (1985) and this study, but not in temperate honeybees (Ribbands, 1952; Lindauer, 1952). The asymmetry in pollen and nectar collection by $M$. beecheii may be a result of corresponding patterns of pollen and nectar presentation by Melipona food plants in tropical lowlands (Roubik, 1989).

\section{Choice of material}

A Melipona forager that successfully returns to the hive tends to revisit the same food source during consecutive flights (Biesmeijer et al., 1998). Consequently, the initial choice for collecting one material or another may influence foraging decisions taken on the next flights, next days or even during a complete career. Therefore we investigated factors that may determine initial material choice. No ontogenetic sequence was found in the collecting of the different types of material. This indicates that age is not of importance for material choice in $M$. beecheii, similar to reports on Melipona favosa (Sommeijer et al., 1983), honeybees (Lindauer, 1952; Ribbands, 1952) and wasps (O'Donnell and Jeanne, 1992). Moreover, the behaviour that a bee performed in her pre-foraging period was not related to the type of foraging career that followed.

Several other factors may have determined the choice of the material that foragers collected, e.g., genetics, colony needs and incidental events. No attempt was made to relate genetic variation to individual foraging behaviour, although it is known that genetically determined task specialisation occurs in other groups of social insects (honeybees: Robinson and Page, 1988, 1989; wasps: O'Donnell, 1996). All Melipona colonies (except those of the M. bicolor group) have a single egg-laying queen that probably mates only once. This would lead to a lower genetic variation between the workers, and consequently less room for genetically determined task allocation than in the polygynous and/or multiple mated groups of social insects. Colony needs are known to influence the choice of foraging commodity in stingless bees (Biesmeijer et al., in prep.) and honeybees (Fewell and Winston, 1992) and may have influenced material choice in the bees studied here. Some types of interactions, either social or non-social, are relatively rare events in a foragers' life, but could well be essential in shaping individual behaviour (e.g., trophallaxis with returning foragers, food source communication, experience on non-collecting flights). It is also known that associative learning in bees can be established after few or even single events (Menzel, 1985). These "rare" events do not show up in the scan sampled data presented here. Focal animal methods are more adequate to reveal the importance of such events. 


\section{Longevity and foraging career}

M. beecheii foragers lived for 51 days on average. This is longer than the 40 days found for M. favosa on Trinidad (Sommeijer, 1984) and the 34 days for honeybees in England (Ribbands, 1952). Longevity was not related to the type of foraging career of a bee and age did not influence the onset of foraging. However, once started its foraging career a pollen forager typically survived for about 12 days of foraging, whereas a nectar forager or pollen-nectar forager died after about 3 days.

Among the hypotheses that explain senescence in insects are the "programmed senescence" hypothesis (mortality is fixed on age) and the "rate-of-living" or burnout senescence hypothesis (longevity is negatively correlated with activity level) (O’Donnell and Jeanne, 1995). M. beecheii foragers were expected to die according to the rate of living hypothesis, because it also seems to hold for honeybees (Neukirch, 1982; Wolf and Schmid-Hempel, 1989) where forager activity level is traded-off with longevity. Our data indeed support the rate of living hypothesis. Highly active individuals (nectar and pollen-nectar foragers) survived fewer foraging hours than less active individuals (pollen foragers) and nectar foragers spent less time outside the colony than pollen foragers (Fig. 4b). In honeybees, high daily activity levels decrease longevity (Neukirch, 1982) as do heavy loads (Wolf and Schmid-Hempel, 1989). Both factors may apply to nectar foragers of Melipona, which make more flight hours per day and probably carry heavier loads than pollen collectors.

However, the observation that pollen and nectar foragers have similar survival probability per flight (Fig. 4c), indicates that the number of flights is not traded-off with longevity. This may imply that collecting a load of pollen or nectar is equally risky. Collecting a pollen load takes $50 \%$ more time than collecting a nectar load, thus pollen foragers have a lower risk per unit foraging time than nectar foragers. This may have various causes. The first explanation could be that the most risky part of a flight is flying to and from the patch. The duration of travelling depends on the distance between hive and patch and the direction and speed of the wind, but not on the material that is carried. Also when the major risk on a foraging flight would occur on choosing a (sub)patch to forage one would expect an equal per flight mortality risk. However, many predators will have time-related capture success (birds, spiders, lizards, ants, reduviid bugs, mantids etc). Some of these predators wait motionless on plants for passing prey. These would render an equal per flower risk for pollen and nectar bees. Thus, if a nectar forager visits a similar number of flowers as a pollen forager, but collecting pollen takes longer per flower the observed pattern of similar per flight risk would be found. No data are available on the rate of flower visitation of Melipona foragers, but honeybees do not seem to spend more time per flower for collecting pollen (Free, 1960,1968). This suggests the possibility that pollen foragers spend the extra time per flight by visiting more flowers per flight than nectar foragers. A lower risk per time unit may result if pollen foragers watch out for predators while hovering to pack their pollen. This would reduce per flower risk and may lead to similar predation risk per flight as for nectar foragers, although more flowers are visited. From our data it can not be decided whether foragers died due to burnout or predation. We can, however, reject the programmed senescence hypothesis. 


\section{Foraging specialisation and harvesting efficiency}

It is generally assumed that in social insect colonies specialists perform tasks more efficiently than generalists and inexperienced individuals (Oster and Wilson, 1978). Recent evidence shows that in bumblebees, foragers are less efficient at the start of there foraging career and that the less efficient foragers are the first to switch to other behaviour when colony needs change (Cartar, 1992). In Melipona beecheii, both foragers that fixated on one material and those that collected two materials occurred in the same age cohort as well as foraging at high activity rates and low activity rates. This allowed comparison of the efficiency of these groups. Foragers that were less specialised did not forage less successfully (Fig. 5). Moreover, the time it took a pollen-nectar forager to collect a pollen load or nectar load was not longer than it took a specialist forager to do so. Thus collecting only one food item or two does not seem to have consequences for foraging efficiency per sé.

Pollen foragers seemed to have a lower probability to collect a load than nectar foragers. This may, however, just be an effect of the longer foraging tenure (in days) of pollen foragers, knowing that the first and last flights of each day are normally the least successful ones (Biesmeijer et al., 1998).

\section{Acknowledgements}

Nydia and Luis Alberto Mena and the other friends from Pozo Azul and El Sur made our stay very pleasant and helped in many ways. Johan van Veen and Henry Arce provided logistic support and laboratory facilities. Saskia Lukács collected the data in El Sur. Mark van Nieuwstadt, Marinus Sommeijer and Hayo Velthuis and two anonymous referees provided useful comments on the manuscript. Cas Kruitwagen and Ingeborg van der Tweel gave statistical advice. This study was made possible through financial support of WOTRO, the Netherlands foundation for research in the tropics (grant to M.J. Sommeijer), the Trueb-maatschappij, the Uyttenboogaart-Eliasen Foundation and the STIR-program of Utrecht University and Lucy Burgers Foundation (ET).

\section{References}

Biesmeijer, J.C., M.G.L. van Nieuwstadt, S. Lukács and M.J. Sommeijer, 1998. The role of internal and external information in foraging decisions of Melipona workers (Hym.: Meliponinae). Behav. Ecol. Sociobiol. 42: 107-116.

Cartar, R.V., 1992. Adjustment of foraging task switching in energy-manipulated wild bumblebee colonies. Anim. Behav. 44:75-87.

Fewell, J.H. and M.L. Winston, 1992. Colony state and regulation of pollen foraging in the honey bee, Apis mellifera L. Behav. Ecol. Sociobiol. 30:387-393.

Free, J.B., 1960. The pollination of fruit trees. Bee world 41:141-151.

Free, J.B., 1968. The foraging behaviour of honeybees (Apis mellifera) and bumblebees (Bombus spp.) on blackcurrant (Ribes nigrum), raspberry (Rubus idaeus) and strawberry (Fragaria $x$ ananassa) flowers. J. Appl. Ecol. 5:157-168.

Heithaus, E.R., 1979. Flower visitation records and resource overlap of bees and wasps in northwest Costa Rica. Brenesia 16:9-52.

Inoue, T., S. Salmah, I. Abbas and E. Yusuf, 1985. Foraging behavior of individual workers and foraging dynamics of colonies of three Sumatran stingless bees. Res. Pop. Ecol. 27:373-392.

Kolmes, S.A., 1985. A quantitative study of the division of labour among worker honey bees. $Z$. Tierphysiol. $68: 287-302$. 
Lindauer, M., 1952. Ein Beitrag zur Frage der Arbeitsteilung im Bienenstaat. Z. vergl. Physiol. 34 : 299-345.

Menzel, R., 1985. Learning in honey bees in an ecological and behavioural context. In: Experimental Behavioural Ecology (B. Hölldobler and M. Lindauer, Eds.), G. Fischer Verlag, Stuttgart, pp. 55-74.

Neukirch, A., 1982. Dependence of the life-span of the honeybee (Apis mellifera) upon flight performance and energy consumption J. Comp. Physiol. 146: 35-40.

O'Donnell, S., 1996. RAPD markers suggest genotypic effects on forager specialization in a eusocial wasp. Behav. Ecol. Sociobiol. 38:83-88.

O'Donnell, S. and R.L. Jeanne, 1990. Forager specialization and the control of nest repair in Polybia occidentalis Olivier (Hymenoptera: Vespidae) Behav. Ecol. Sociobiol. 27: 359-364.

O’Donnell, S. and R.L. Jeanne, 1992. Life-long patterns of foraging behaviour in a tropical swarmfounding wasp: effects of specialisation and activity level on longevity. Anim. Behav. 44: $1021-1027$.

O'Donnell, S. and R.L. Jeanne, 1995. Implications of senescence patterns for the evolution of age polyethism in eusocial insects. Behav. Ecol. 6:269-273.

Oster, G.F. and E.O. Wilson, 1978. Caste and Ecology in the Social Insects. Princeton University Press, Princeton, $352 \mathrm{pp}$.

Pasteels, J.M., J.-L, Deneubourg and S. Goss, 1987. Self-organization mechanisms in ant societies (I): trail recruitment to newly discovered food resources. Experientia Suppl. 54:155-177.

Ribbands, C.R., 1952. Division of labour in the honeybee community. Proc. Royal Soc. $140 B: 32-43$.

Robinson, G.E. and R.E. Page, Jr., 1988. Genetic determination of guarding and undertaking in honeybee colonies. Nature 333: 356-358.

Robinson, G.E. and R.E. Page, Jr., 1989. Genetic determination of nectar foraging, pollen foraging, and nest-site scouting in honey bee colonies. Behav. Ecol. Sociobiol. 24:317-323.

Roubik, D.W., 1989. Ecology and Natural History of Tropical Bees. Cambridge University Press, Cambridge, 514 pp.

Roubik, D.W. and S.L. Buchmann, 1984. Nectar selection by Melipona and Apis mellifera (Hymenoptera: Apidae) and the ecology of nectar intake by bee colonies in a tropical forest. Oecologia $61: 1-10$.

Sakagami, S.F. and H. Fukuda, 1968. Life tables for worker honeybees. Res. Popul. Ecol. 10:127-139.

Shannon, C.E. and W. Weaver, 1949. The Mathematical Theory of Communication. University of Illinois Press, Urbano Ill., 117 pp.

Simões, D. and L.R. Bego, 1991. Division of labor, average life span and life table in Nannotrigona (Scaptotrigona) postica Latreille (Hymenoptera, Apidae, Meliponinae). Naturalia 16: 81-97.

Sommeijer, M.J., 1984. Distribution of labor among workers of Melipona favosa F.: age-polyethism and worker oviposition. Insectes soc. 31:171-184.

Sommeijer, M.J., G.A. de Rooy, W. Punt and L.L.M. de Bruijn, 1983. A comparative study of foraging behaviour and pollen resources of various stingless bees (Hym., Meliponinae) and honey bees (Hym., Apinae) in Trinidad, West-Indies. Apidologie 14: 205-224.

Wolf, T.J. and P. Schmid-Hempel, 1989. Extra loads and foraging life span in honeybee workers J. Anim. Ecol. 58: 943-954.

Received 11 August 1997;

revised 13 February 1998;

accepted 24 February 1998. 